\title{
Vertical cavity surface emitting laser action of an all monolithic ZnO-based microcavity
}

\author{
S. Kalusniak, S. Sadofev, S. Halm $*$ and F. Henneberger \\ Institut für Physik, Humboldt-Universität zu Berlin, Newtonstr. 15, 12489 Berlin, Germany
}

(Dated: November 13, 2018)

\begin{abstract}
We report on room temperature laser action of an all monolithic ZnO-based vertical cavity surface emitting laser (VCSEL) under optical pumping. The VCSEL structure consists of a $2 \lambda$ microcavity containing $8 \mathrm{ZnO} / \mathrm{Zn}_{0.92} \mathrm{Mg}_{0.08} \mathrm{O}$ quantum wells embedded in epitaxially grown $\mathrm{Zn}_{0.92} \mathrm{Mg}_{0.08} \mathrm{O} / \mathrm{Zn}_{0.65} \mathrm{Mg}_{0.35} \mathrm{O}$ distributed Bragg reflectors (DBRs). As a prerequisite, design and growth of high reflectivity $\mathrm{DBR}$ based on $\mathrm{ZnO}$ and $(\mathrm{Zn}, \mathrm{Mg}) \mathrm{O}$ for optical devices operating in the ultraviolet and blue-green spectral range are discussed.
\end{abstract}

Semiconductor lasers operating in the ultraviolet (UV) and blue spectral range have become of great technological importance, e.g., for data storage applications. Compared to the commonly employed edge-emitting devices, vertical cavity surface emitting lasers (VCSELs) offer several advantages such as single mode emission, a circular beam profile, and the possibility for integration into two dimensional arrays. VCSELs based on GaN and its alloys reached a promising stage of development [1] and laser devices working in the strong exciton-photon coupling regime, so called polariton lasers, have been demonstrated at room temperature [2]. In principle, with $\mathrm{ZnO}$ based alloys, a similar spectral range can be covered as with the $(\mathrm{Al}, \mathrm{In}, \mathrm{Ga}) \mathrm{N}$ heterosystem. Room temperature lasing of $(\mathrm{Zn}, \mathrm{Cd}) \mathrm{O} / \mathrm{ZnO}$ quantum well $(\mathrm{QW})$ structures was achieved from UV to green wavelengths [3]. In the strong coupling regime, $\mathrm{ZnO}$ was predicted to be even superior due to its high oscillator strength and exciton binding energy [4, 5]. However, necessary prerequisites to both VCSELs and polariton lasers are microcavities (MCs) with a high quality factor and good optical quality $\mathrm{ZnO}$ active layers. So far only hybrid MCs [6-9] consisting of, e.g., an epitaxially grown GaN-based bottom distributed Bragg reflector (DBR), a $\mathrm{ZnO}$ active layer, and a top dielectric DBR have been employed.

In this letter, we report on the monolithic growth of $\mathrm{ZnO}$ and $(\mathrm{Zn}, \mathrm{Mg}) \mathrm{O}$ based DBRs and MCs by radicalsource molecular beam epitaxy (MBE). With a properly chosen DBR ternary alloy composition, it is possible to obtain high reflectivities with a moderate number of mirror pairs in the range from $375 \mathrm{~nm}$ to $500 \mathrm{~nm}$. Finally, we demonstrate an UV emitting all-ZnO VCSEL.

The samples are grown in a commercial DCA-450 MBE apparatus equipped with standard metal sources and a radical plasma cell for oxygen. A-plane (112̄0) sapphire wafers are used as substrates. The $(\mathrm{Zn}, \mathrm{Mg}) \mathrm{O}$ DBRs and MCs containing $\mathrm{ZnO} /(\mathrm{Zn}, \mathrm{Mg}) \mathrm{O}$ QWs are grown without interruption at $T_{\mathrm{g}}=340{ }^{\circ} \mathrm{C}$ with an oxygen limited growth rate of $330 \mathrm{~nm} / \mathrm{h}$, which was previously determined from oscillations in the specular beam intensity of in situ reflected high-energy electron diffraction (RHEED) [3]. Note that the low $T_{\mathrm{g}}$ allows for the growth
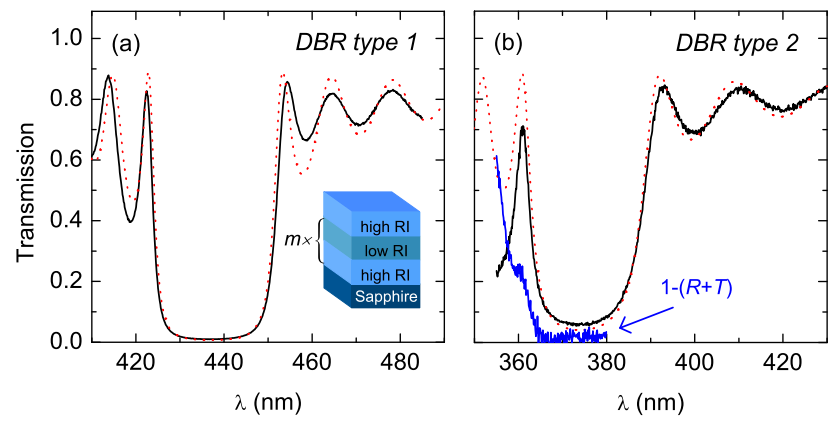

FIG. 1: (Color online) Optical properties of ZnO-based DBRs type 1 and 2. Transmission spectra (solid lines) and calculated transmission (dotted lines) of a $\mathrm{ZnO} / \mathrm{Zn}_{0.65} \mathrm{Mg}_{0.35} \mathrm{O} \mathrm{DBR}$ (a) and a $\mathrm{Zn}_{0.92} \mathrm{Mg}_{0.08} \mathrm{O} / \mathrm{Zn}_{0.65} \mathrm{Mg}_{0.35} \mathrm{O} \mathrm{DBR}$ (b). Inset in (a): Schematic layout (not true to scale). In (b), absorption $A=$ $1-(R+T)$ is added as reference (see arrow).

of both $\mu$ m-thick, high Mg-content ( $\mathrm{Zn}, \mathrm{Mg}) \mathrm{O}$ layers with a surface roughness of only a few monoatomic layers as well as high optical quality $\mathrm{ZnO}$ QWs [10]. Individual layer thicknesses are defined via growth times. Two effusion cells for $\mathrm{Mg}$ are used in order to modulate the alloy composition of ternary $\mathrm{Zn}_{1-x} \mathrm{Mg}_{x} \mathrm{O}$ layers. The overall structure quality is continuously monitored by detecting the RHEED pattern of the growing surface.

Two types of $\mathrm{ZnO}$-based DBRs have been realized: $\quad \mathrm{ZnO} / \mathrm{Zn}_{1-x} \mathrm{Mg}_{x} \mathrm{O}$ (type 1) and $\mathrm{Zn}_{1-y} \mathrm{Mg}_{y} \mathrm{O} / \mathrm{Zn}_{1-x} \mathrm{Mg}_{x} \mathrm{O}$ (type 2) for blue emitting $(\mathrm{Zn}, \mathrm{Cd}) \mathrm{O}$ and UV emitting $\mathrm{ZnO}$ optical devices, respectively. Figure 1(a) shows the transmission spectrum of a type- 1 DBR with $m=27$ pairs of $\lambda / 4$-layers of $\mathrm{ZnO} / \mathrm{Zn}_{0.65} \mathrm{Mg}_{0.35} \mathrm{O}$ and an additional $\lambda / 4$-thick $\mathrm{ZnO}$ cap layer (schematic layout: see inset). $\mathrm{A} \mathrm{Mg}$ content of $x=0.35$ slightly below the solubility limit was selected for the low refractive index (RI) layer 10] in order to reach a large RI contrast $(\Delta n / n \approx 10 \%)$ while still allowing for stable two-dimensional growth. For the specific layer thicknesses used, the stop band is centered at $\lambda_{\mathrm{SC}}=436 \mathrm{~nm}$ and exhibits a spectral width of about $180 \mathrm{meV}$. The number of mirror pairs is sufficient to reduce the transmission through the 
stack at $\lambda_{\mathrm{SC}}$ to $T=0.01$. In type- 2 DBRs aimed for $\mathrm{ZnO}$ devices, the high RI material has to contain a few percent of $\mathrm{Mg}$ to avoid absorption in the mirrors. We found that $y=0.08$ is a good choice which allows to keep $\Delta n / n$ as large as possible. The transmission of a $m=15$ pairs $\mathrm{Zn}_{0.92} \mathrm{Mg}_{0.08} \mathrm{O} / \mathrm{Zn}_{0.65} \mathrm{Mg}_{0.35} \mathrm{O}-\mathrm{DBR}$ with an additional $\lambda / 4-\mathrm{Zn}_{0.92} \mathrm{Mg}_{0.08} \mathrm{O}$ layer is depicted in Fig. 1(b). At the stop band center $\lambda_{\mathrm{SC}}=375 \mathrm{~nm}$, the transmission is reduced to $T=0.055$. The transmission values can be directly converted into the DBR reflection $R=1-T$ if absorption is negligible. We have ensured this by recording complementary reflectivity spectra. For demonstration, absorption $A=1-(R+T)$ is shown in Fig. 1(b) (see arrow) for the type-2 DBR, where $\lambda_{\mathrm{SC}}$ is closest to the high RI layer absorption onset. In fact, the presence of spectrally sharp absorption edges, also for ternary $(\mathrm{Zn}, \mathrm{Mg}) \mathrm{O}$ layers, is an essential feature for the DBR functionality we report on here. We find thus $R=0.99$ and $R=0.945$ for the type- 1 and type- 2 DBRs in Fig. 1, respectively.

To model the experimental data by transfer matrix calculations [11], we describe the RI dispersion by a firstorder Sellmeier equation

$$
n(\lambda)=\sqrt{A+\frac{B \lambda^{2}}{\lambda^{2}-C^{2}}},
$$

and neglect absorption [see dotted lines in Fig. 1(a) and (b)]. For $\mathrm{ZnO}$, where $n(\lambda)$ is well-established, the parameters $A, B$ and $C$ shown in Table \ result from a least-square fit of Eq. (11) to the data of Ref. [12]. For $(\mathrm{Zn}, \mathrm{Mg}) \mathrm{O}$, RI literature data still differ strongly and cover only part of the wavelength range of interest here [13, 14]. Our values for $x=0.08$ and $x=0.35$ in Table \ correspond to a "best guess" for which the transfer matrix model reproduces the transmission spectra of five experimentally realized DBRs very well (type 1 : $\lambda_{\mathrm{SC}}=422 \mathrm{~nm}$ and $436 \mathrm{~nm}$; type $2: \lambda_{\mathrm{SC}}=375 \mathrm{~nm}$, $382 \mathrm{~nm}$, and $394 \mathrm{~nm}$ ). The resulting dispersion curves are in reasonable agreement with Ref. [13]. The good match between model and experiment in the stop band region further confirms that absorption is not important here.

With the help of the RI dispersion curves, we are able to explore theoretically the potential of DBRs type 1 and 2. Results of respective calculations are summarized in Fig. 2. In Fig. 2(a), the number of mirror pairs $m$ re-

TABLE I: Sellmeier values $A, B$ and $C$ for DBR layers with $\mathrm{Mg}$ content $x$.

\begin{tabular}{cccc}
\hline \hline$x$ & $A$ & $B$ & $C(\mathrm{~nm})$ \\
\hline 0.00 & 3.21 & 0.55 & 337.4 \\
0.08 & 3.13 & 0.53 & 317.4 \\
0.35 & 1.00 & 2.29 & 180.0 \\
\hline \hline
\end{tabular}
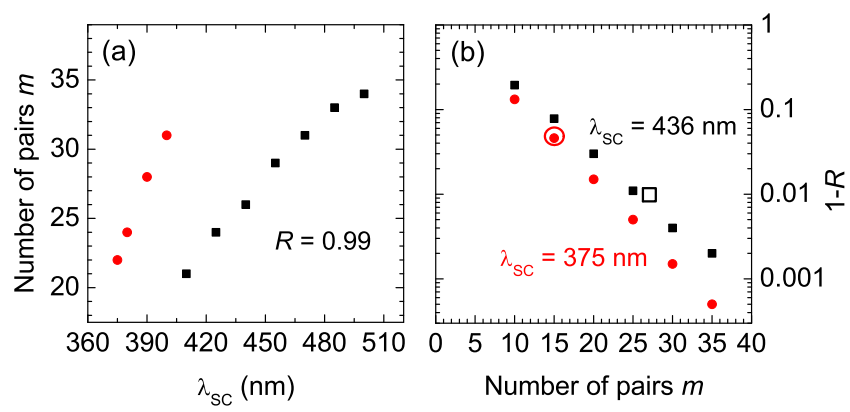

FIG. 2: (Color online) Calculated properties of ZnO-based DBRs type 1 (squares) and 2 (circles). (a) Number of mirror pairs $m$ required to achieve $R=0.99$ as a function of $\lambda_{\mathrm{SC}}$. (b) Variation of reflectivity with mirror pair number $m$ at fixed $\lambda_{\mathrm{SC}}$. Experimental results for DBRs in Fig. 1 are marked by open symbols.

quired for $R=0.99$ is depicted as a function of $\lambda_{\mathrm{SC}}$. At short wavelengths, absorption of the high RI material limits the use of a given DBR type. When aiming at longer wavelengths, an increasing number of mirror pairs is necessary, which results from the decreasing RI contrast between the layers. However, with less than 35 mirror pairs (equivalent to a DBR thickness $\lesssim 4 \mu \mathrm{m}$ ), high reflectivity ZnO-based DBRs can be realized which cover a wavelength range from $375 \mathrm{~nm}$ up to $500 \mathrm{~nm}$. For DBRs with a small $\lambda_{\mathrm{SC}}$, i.e., DBRs that do not work too far off the excitonic resonance of the high RI material, the index contrast is large enough to achieve very high reflectivities with only a moderate number of mirror pairs. As shown in Fig. 2(b), a 35 mirror pair type-1 DBR operating at $\lambda_{\mathrm{SC}}=436 \mathrm{~nm}$ can exhibit a reflectivity of 0.998 , and a type- $2 \mathrm{DBR}$ with $\lambda_{\mathrm{SC}}=375 \mathrm{~nm}$ reaches approximately the same value with only 30 mirror pairs. This makes the realization of monolithic $(\mathrm{Zn}, \mathrm{Cd}) \mathrm{O}$ and ZnO-VCSELs feasible.

Based on the data and calculations of Figs. 1 1and 2, we have defined a design for a ZnO VCSEL. We use type-2 DBRs with 28 and 25 layer pairs as lower and upper mirrors, respectively. The individual layer thicknesses are increased slightly to shift $\lambda_{\mathrm{SC}}$ to $380 \mathrm{~nm}$. A total number of eight $4 \mathrm{~nm}$ wide $\mathrm{ZnO} / \mathrm{Zn}_{0.92} \mathrm{Mg}_{0.08} \mathrm{O}$ QWs are positioned near the electric field antinodes of a $\mathrm{Zn}_{0.92} \mathrm{Mg}_{0.08} \mathrm{O}$ cavity with a total thickness of $2 \lambda$. Correct $\mathrm{MC}$ growth is confirmed by normal incidence large-area $\left(1 \mathrm{~mm}^{2}\right)$ reflectivity measurement. As can be seen in Fig. 3(a) (black curve, right axis) $\lambda_{\mathrm{SC}}$ is close to the desired position and a reflectivity dip due to the cavity is observed at $384 \mathrm{~nm}$. The spectral width of the cavity mode $\Delta E=7 \mathrm{meV}$ corresponds to a quality factor of $Q \approx 430$, though this is only a lower limit to $Q$, since inhomogeneous broadening is known to play a role.

The device is optically excited by an excimer laser pumped dye laser with a pulse duration of $20 \mathrm{~ns}$ focused to a $60 \mu \mathrm{m}$ diameter spot. At the excitation wave- 

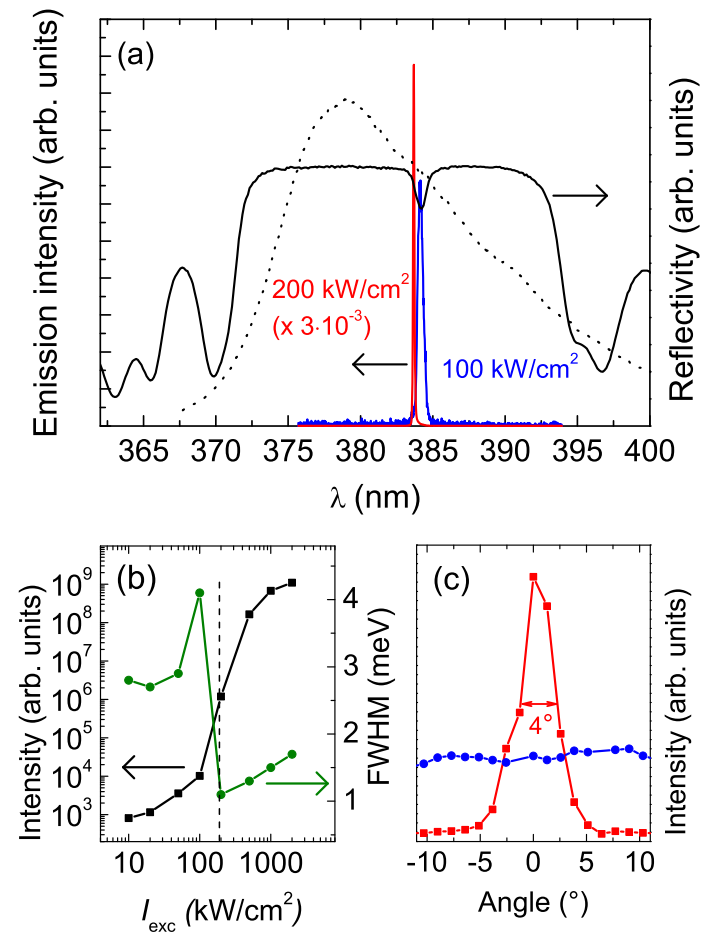

FIG. 3: FIG. 3: (Color online) Optical properties of a VCSEL device based on type-2 DBRs. (a) Normal incidence reflectivity (right axis), surface emission (left axis) for $I_{\text {exc }}=100 \mathrm{~kW} / \mathrm{cm}^{2}$ and $I_{\text {exc }}=200 \mathrm{~kW} / \mathrm{cm}^{2}$, and low-density MQW edge PL (dotted curve). (b) Integrated surface emission intensity (squares, left axis) and FWHM linewidth (circles, right axis) as a function of $I_{\text {exc }}$. The lasing threshold $I_{\text {th }}=190 \mathrm{~kW} / \mathrm{cm}^{2}$ is marked by a dashed line. (c) Angle dependent, spectrally integrated emission intensity at $I_{\text {exc }}=$ $100 \mathrm{~kW} / \mathrm{cm}^{2}$ (circles) and $I_{\mathrm{exc}}=200 \mathrm{~kW} / \mathrm{cm}^{2}$ (squares).

length $\lambda_{\text {exc }}=364 \mathrm{~nm}$, reflectivity of the DBR is $20 \%$ and absorption is small. Figure [3(a) (left axis) shows surface cavity emission spectra at excitation densities of $I_{\text {exc }}=100 \mathrm{~kW} / \mathrm{cm}^{2}$ and $200 \mathrm{~kW} / \mathrm{cm}^{2}$, as well as the lowdensity multiple QW (MQW) photoluminescence (PL) collected from the sample edge (dotted curve) as reference. At low temperature ( $7 \mathrm{~K}$, not shown), the full width at half maximum (FWHM) of the MQW PL is $10 \mathrm{meV}$ implying that optical quality of the MQWs did not deteriorate notably by growth on the $2.6 \mu \mathrm{m}$ thick lower DBR. At room temperature, on which we focus here, the FWHM is $135 \mathrm{meV}$ and the peak wavelength is at $379 \mathrm{~nm}$. Previous studies on the laser action of such MQW structures in an edge-emitting geometry have revealed that optical gain emerges on the low-energy side of the spontaneous-emission PL band and is related to localized states [15]. We have set the center wavelength of the DBRs to this spectral range, i.e., far below the MQW absorption peak which is even high-energy shifted with respect to the PL maximum by some $10 \mathrm{meV}$. Polariton effects related to strong exciton-photon coupling are thus unlikely to play a major role.
Comparing the cavity emission at $I_{\mathrm{exc}}=100 \mathrm{~kW} / \mathrm{cm}^{2}$ and $200 \mathrm{~kW} / \mathrm{cm}^{2}$, two strong indications for a transition to VCSEL action are worth to notice: First, the emission intensity increases by more than two orders of magnitude, and second, its FWHM decreases abruptly by a factor of 4 . The evolution of both quantities with excitation density is depicted in Fig. 3(b), signifying a well-defined threshold. The slight shift observed between the emission peaks below and above threshold might be due to changes in the RIs. Polarization fields affecting the lowdensity PL are screened off at the excitation levels close to threshold. To confirm the realization of a VCSEL, we recorded emission-angle resolved spectra using a microscope objective with a 20x magnification and a numerical aperture of N.A. $=0.5$ [see Fig. 3(c)]. As expected for a VCSEL [16], the emission above threshold is restricted to a narrow cone about the surface normal with an angular FWHM of $4^{\circ}$ only. Additionally, we find that the emission above threshold becomes strongly linearly polarized, probably due to the anisotropy of the sapphire substrate.

In conclusion, we have shown that monolithically grown DBRs based on $\mathrm{Zn}_{1-y} \mathrm{Mg}_{y} \mathrm{O} / \mathrm{Zn}_{1-x} \mathrm{Mg}_{x} \mathrm{O}$ heterostructures can be used as high reflectivity mirrors for $\mathrm{ZnO}$ and $(\mathrm{Zn}, \mathrm{Cd}) \mathrm{O}$ active-layer MCs. In particular, we demonstrated the realization of a VCSEL operating at $\lambda=384 \mathrm{~nm}$ at room temperature. Current work is directed towards the strong-coupling regime, which may be reached by lowering the temperature or adapting the $\mathrm{MC}$ design.

This work was supported by Deutsche Forschungsgemeinschaft within SFB 555.

* Electronic address: simon.halm@physik.hu-berlin.de

[1] A recent overview on GaN-based VCSELs is found in the work of R. Shimada and H. Morkoç, Proc. IEEE 98, 1113 (2010).

[2] S. Christopoulos, G. Baldassarri Höger von Högersthal, A. J. D. Grundy, P. G. Lagoudakis, A. V. Kavokin, J. J. Baumberg, G. Christmann, R. Butté, E. Feltin, J.-F. Carlin, and N. Grandjean, Phys. Rev. Lett. 98, 126405 (2007).

[3] S. Kalusniak, S. Sadofev, J. Puls, and F. Henneberger, Laser Photonics Rev. 3, 233 (2009).

[4] M. Zamfirescu, A. Kavokin, B. Gil, G. Malpuech, and M. Kaliteevski, Phys. Rev. B 65, 161205(R) (2002).

[5] S. Faure, T. Guillet, P. Lefebvre, T. Bretagnon, and B. Gil, Phys. Rev. B 78, 235323 (2008)

[6] R. Shimada, J. Xie, V. Avrutin, Ü. Özgür, and H. Morkoç, Appl. Phys. Lett. 92, 011127 (2008).

[7] J. R. Chen, T. C. Lu, Y. C. Wu, S. C. Lin, W. R. Liu, W. F. Hsieh, C. C. Kuo, and C. C. Lee, Appl. Phys. Lett. 94, 061103 (2009).

[8] S. Faure, C. Brimont, T. Guillet, T. Bretagnon, B. Gil, F. Médard, D. Lagarde, P. Disseix, J. Leymarie, J. ZuñigaPérez, M. Leroux, E. Frayssinet, J. C. Moreno, F. Semond, and S. Bouchoule, Appl. Phys. Lett. 95, 121102 
(2009).

[9] C. Sturm, H. Hilmer, R. Schmidt-Grund and M. Grundmann, New J. Phys. 11, 073044 (2009).

[10] S. Sadofev, S. Blumstengel, J. Cui, J. Puls, S. Rogaschewski, P. Schäfer, Yu. G. Sadofyev, and F. Henneberger, Appl. Phys. Lett. 87, 091903 (2005).

[11] M. Born and E. Wolf, Principles of Optics, 6th edition (Pergamon, Oxford, 1993).

[12] E. Mollwo, Z. Angew. Phys. 6, 257 (1954).

[13] C. W. Teng, J. F. Muth, Ü. Özgür, M. J. Bergmann, H. O. Everitt, A. K. Sharma, C. Jin, and J. Narayan, Appl.
Phys. Lett. 76, 979 (2000).

[14] R. Schmidt, B. Rheinländer, M. Schubert, D. Spemann, T. Butz, J. Lenzner, E. M. Kaidashev, M. Lorenz, A. Rahm, H. C. Semmelhack, and M. Grundmann, Appl. Phys. Lett. 82, 2260 (2003).

[15] J. Cui, S. Sadofev, S. Blumstengel, J. Puls, and F. Henneberger, Appl. Phys. Lett. 89, 051108 (2006)

[16] D. Bajoni, P. Senellart, A. Lemaître, and J. Bloch, Phys. Rev. B 76, 201305(R) (2007). 